\title{
Real Estate and Infrastructure Resolution
}

\author{
Jayanth R. Varma
}

\section{Sebastian Morris}

W. P. No. 2019-09-01

September 2019

The main objective of the working paper series of the IIMA is to help faculty members, research staff and doctoral students to speedily share their research findings with professional colleagues and test their research findings at the pre-publication stage. IIMA is committed to maintain academic freedom. The opinion(s), view(s) and conclusion(s) expressed in the working paper are those of the authors and not that of IIMA.

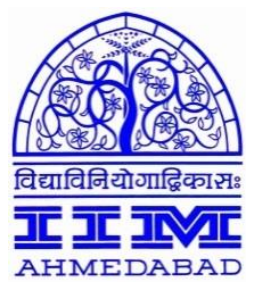

INDIAN INSTITUTE OF MANAGEMENT

AHMEDABAD-380 015

INDIA 


\title{
Real Estate and Infrastructure Resolution
}

\author{
Jayanth R. Varma ${ }^{1}$ \\ Sebastian Morris
}

\begin{abstract}
We propose a mechanism that uses the financial markets to mobilize the resources of a large population of investors, to revive the impaired assets in the real sector in India today. This should also allow the economy to escape from the strangle hold of the "doom loop", in which the financial sector, the infrastructure and real estate sectors and the economy in general through their feedback effects on each other, portend to take the economy deeper into the recession. The mechanism where the government covers the left tail risk in infrastructure and real estate, has the potential to revive these assets to the benefit of the homebuyers, users and the public, with the government earning a handsome return, while being fair to the developers as well. With such a mechanism in place, in the future, developers would know that using distressed public value to their advantage would not be possible in the future.
\end{abstract}

\footnotetext{
1 Professors at the Indian Institute of Management, Ahmedabad. Emails: 


\section{Introduction}

The economy which had been slowing for many years has now taken a dive for the worse. The end of the recession is now where in sight, and time for emergency measures is right here. Mere monetary measures would not work. Crucial to the revival and to bring back the efficacy of monetary measures would be to put the real estate and infrastructure sectors back on the rails. Loans to infrastructure and real estate are a large part of the bad loan problem of banks and non- bank lenders. According to the Financial Stability Report of the Reserve Bank of India for June 2019 , nearly $18 \%$ of the bank lending to infrastructure was non performing and infrastructure accounts for over $36 \%$ of total bank lending to industry. Overall NPAs are in the range of $12 \%$ of all advances of the scheduled commercial banks. The same report also highlights the fact that 46 per cent of the total loans for the top 5 housing finance companies consisted of non-mortgage loans indicating that loans to real estate developers and the like were almost as large as their home loan portfolio. While the Insolvency and Bankruptcy Code (IBC) holds out some hope of effective resolution of bad debts in the tradeable goods sector, Real Estate and Infrastructure distressed assets pose a much more intractable problem and require a very different toolkit.

Merely bailing out the failing/ failed developers would only further cronyism. In what follows we propose a mechanism that is in the interest of the state, and most importantly would also protect the home buyers, and could revive the financial sector and the economy, while being fair to the developer. It would also arrest the tendency of capital to use the interest of the public or of a vast number of clients or users to finesse the state into their rescue.

\section{Real Estate and Infrastructure are different}

Infrastructure and real estate have a number of characteristics that make it harder for the financial system to cope with a crisis in this sector.

\section{Market failures}

Infrastructure and real estate involve a local (spatial) monopoly, with large, typically positive externalities, but with idiosyncratic market values. This is because the market value is dependent on the portion that is appropriable. And connectedness location (distance from other economic activities), government regulation on asset use, functioning of various complementary markets, and design, and most importantly integration with complementary networks and services are all determinants of overall value

Being also non-tradeable, they therefore cannot fall back on a market outside the narrow demand territory. A tradeable sector asset like a steel plant has a floor asset value based on border prices of inputs and outputs even in a situation where domestic demand has collapsed. This truncates the left tail of the asset value distribution and mitigates the tail risks of the tradeable goods sector. There is no floor on Real Estate and Infrastructure asset values independent of the state of the domestic economy. There is no alternate value to assets in harness - all costs are sunk and non-deployable outside the business and the space. 


\section{Sovereign risks}

Real Estate and Infrastructure are also exposed to sovereign risk (environmental regulation and government policy). Conversely, the government can unlock vast social and private values by removing distortions in the regulation of this sector.

Restructuring and liquidation of Real Estate and Infrastructure suffers from an additional handicap. Due to strategic considerations, political sensitivity and the like, there is a reluctance to allow foreign bidders to control too much of these assets even if they may be attracted to these assets because of near zero and even negative interest rates in much of the developed economies today. Even when opened up, given the idiosyncrasies, foreign investors may only be able to bring the value of lower cost of capital, but typically not of the changes in the real factors - land use, scale and scope, which improves appropriability.

\section{The Doom Loop}

Real Estate and Infrastructure can therefore create a doom loop as sketched in figure below. Problems in Real Estate and Infrastructure debilitates the financial sector through rising nonperforming assets. A dysfunctional financial sector further weakens the economy through credit tightening. A weak economy devastates Real Estate and Infrastructure through the demand channel.

\section{Overview of Proposed Resolution Mechanism}

Given these unique characteristics of Real Estate and Infrastructure, a purely market based, piecemeal, asset by asset approach to resolution would be of limited value in handling widespread distress in this sector. Instead, we take a systemic view, and contemplate the sovereign playing a more forceful role in the resolution. We describe the proposed mechanism focusing on real estate, but most of the ideas can be adapted to infrastructure as well.

\section{Government bears tail-risk}

Successful resolution of real estate must deal with the tail risk arising from non-tradability and regulatory risk. We believe that while the private sector can cope with project level business risks. Only the sovereign can absorb the tail risks posed by the doom loop and by uncertainty about its own conduct. The resolution mechanism must be so designed that the sovereign does not suffer a loss in bearing this tail risk; in fact, the expectation should be that the sovereign would make a profit from the whole transaction in the long run.

\section{Pooling is necessary}

The ability of markets to discover fair value of real estate is subject to a high degree of asymmetric information since existing developers would have greater knowledge of the characteristics of their own projects. The best way to deal with this problem is to bundle a large number of assets into a pool and auction the pool as a whole instead of auctioning individual assets. Standard industry valuation models would be quite adequate to value the pool as a whole. 
The financial distress of the existing developers as well as their lenders may make such a pooling possible even on a voluntary basis. It may also be possible to create a legal basis for such pooling if the voluntary route proves to be too slow or unreliable.

Indian financial markets are deep enough to allow a pool of assets to be financed by issuance of securities (equity and debt) to a broad based ownership base. This means that if the doom loop is decisively broken and replaced by a virtuous circle of booming economy and rising real estate values, the gains would be distributed to a large population of investors and not to a handful of crony capitalists.

\section{Internalising positive externalities through scale and scope}

A large pooled vehicle, covering assets that are co-located could internalize many of the positive externalities. The vehicle could for example make investments in new common infrastructure that could yield significant gains to many individual projects in the pool. Resolution via pooling therefore creates an opportunity to unlock large social value, and the resolution mechanism can be so designed that the newly unlocked value is shared between the investors in the pool, the original lenders to the individual projects, the sovereign and other stakeholders.

\section{Operational capability}

There is enough operational capability in the form of public sector organizations and select independent private sector agencies to create and manage these pooled vehicles. This would mitigate conflicts of interest involving the existing developers, their lenders, the ultimate clients, and the new investors.

There are precedents from across the world for resolution vehicles set up to deal with real estate induced financial crises. For example, during the subprime crisis, the United States used a number of vehicles under the Federal Reserve to absorb the tail loss (second loss cover) of real estate loans. These vehicles (known as Maiden Lane) played a critical role in stabilizing the US banking system after the crisis.

\section{Hedonic pricing to determine base values}

To establish the valuation of real estate assets, we propose to use the hedonic regression model which is a well-established valuation model in the real estate industry. The Handbook on Residential Property Prices Indices (published by Eurostat, International Labour Organization (ILO), International Monetary Fund (IMF), Organisation for Economic Cooperation and Development (OECD), United Nations Economic Commission for Europe (UNECE) and the World Bank) provide the following evaluation of the method:

"The hedonic method is probably the most efficient method for making use of the available data. ... The overall evaluation of the hedonic method is that it is probably the best method that could be used in order to construct constant quality [Residential Property Prices Indices] for various types of property."

REA as the SPV

The government sets up a real estate agency (REA) to buy distressed real estate assets from the banks at a tentative valuation established by the hedonic regression model. (For simplicity, 
we are assuming that the valuation of the assets is less than the total debt, and therefore the equity of the original developers in the project has been fully wiped out. The general case where the developer has some residual equity still left can be handled quite easily). The REA aggregates these assets together into a large geographically diversified pool and transfers this pool into a Special Purpose Vehicle (Pool SPV).

\section{Client interest}

A legal provision that when clients (especially homebuyers) have lost much because of delays and unfinished /impaired assets, the government has the right to take over the impaired assets can help. This is important because developers especially of infrastructure like roads, and public facilities take recourse to the public interest value in their projects to force ex-post the government to cover part of their losses. With our proposal the government can now enter to the advantage of the users (public) and home-buyers, rather than that to the developer per se.

The REA appoints a public sector organization or an independent and credible private sector agency as the Operating Agency to operate and manage the Pool SPV on a fee basis.

\section{Pooled SPV valuation through auction}

The value of the Pool SPV is established by an auction with a reservation price which would ensure that the discovered price is not too far below the model price. Alternatively, the price discovery could be achieved by a sale of equity and debt securities (tranches of the pool) through the book building process used in normal public offering of shares by companies.

The final price paid to each of the original lenders would be its pro-rata share of the total value of the Pool SPV as determined by the auction. In addition, the lenders would receive a pro rata share of Appreciation Rights as described later.

\section{Government's role and the REA}

The Operating Agency would sell the assets over a period of 5-10 years (after completing the unfinished development where appropriate). The cash flows from this sale (net of the Guarantee Commission described below) would pay off the debt and equity securities issued by the Pool SPV.

The REA (backed by the sovereign) provides a second loss cover to the Pool SPV. If the present value of all recovery from the pool assets is less than say $80 \%$ of the hedonic regression valuation, the REA would absorb this loss and reimburse it to the Pool SPV. This is the mechanism by which the tail risk is transferred to the sovereign which is the only entity capable of bearing this risk.

The Pool SPV would pay an annual Guarantee Commission to the REA as a percentage of the pool assets. If necessary, this can be supplemented by a share of profits above a watermark (say $40 \%$ ) earned by the Pool SPV. This compensation structure would be set at a level such that the sovereign would be expected to make a small profit out of the transaction. 


\section{Other additional options to enhance value}

The Pool SPV would also have a few other monetization avenues.

- Unutilized floor space index (FSI) limits in some projects (with poor commercial prospects) could be sold in the market or transferred to other projects in the pool.

- The Pool SPV may create new common infrastructure that creates large incremental value for many projects in the pool.

- The Pool SPV may negotiate with the government for relaxations in FSI or zoning regulations that unlock social value, and it may be able to internalize a significant part of this social value because of its scale and scope. Of course, as part of these negotiations, the government may seek some share of these gains, but a large part of the gains would still accrue to the Pool SPV.

A mechanism of Appreciation Rights would be created so that a modest share of these additional sources of value are paid to the original lenders who took a large haircut while transferring the assets to the Pool SPV.

\section{Conclusion}

We have outlined a comprehensive resolution mechanism that can clean up the mess in the real estate sector, stabilize the financial system, and help put the economy back on the growth path. Much of the same ideas could be used for infrastructure as well, by replacing the hedonic regression with more appropriate valuation models. For example, the standard gravity model would be quite suitable for valuing a pool of road projects. Similarly, in electricity generation PPPs, where the developer took large risks with regard to escalable costs, the eroded value could set the takeover value, while the price could be determined by an auction now under a policy that allows fuel prices (in a thick market) as a pass-thru, allowing the government (SPV specially set up for the process) to appropriate the difference after paying the lenders their own eroded value.

By using financial markets to mobilize the resources of a large population of investors, our proposals would free these sectors from the grip of crony capitalists and make it easier for the state to carry our meaningful sectoral reforms that unlock social value. With such a mechanism in place developers would know that using distressed public value to their advantage would not be possible in the future. 


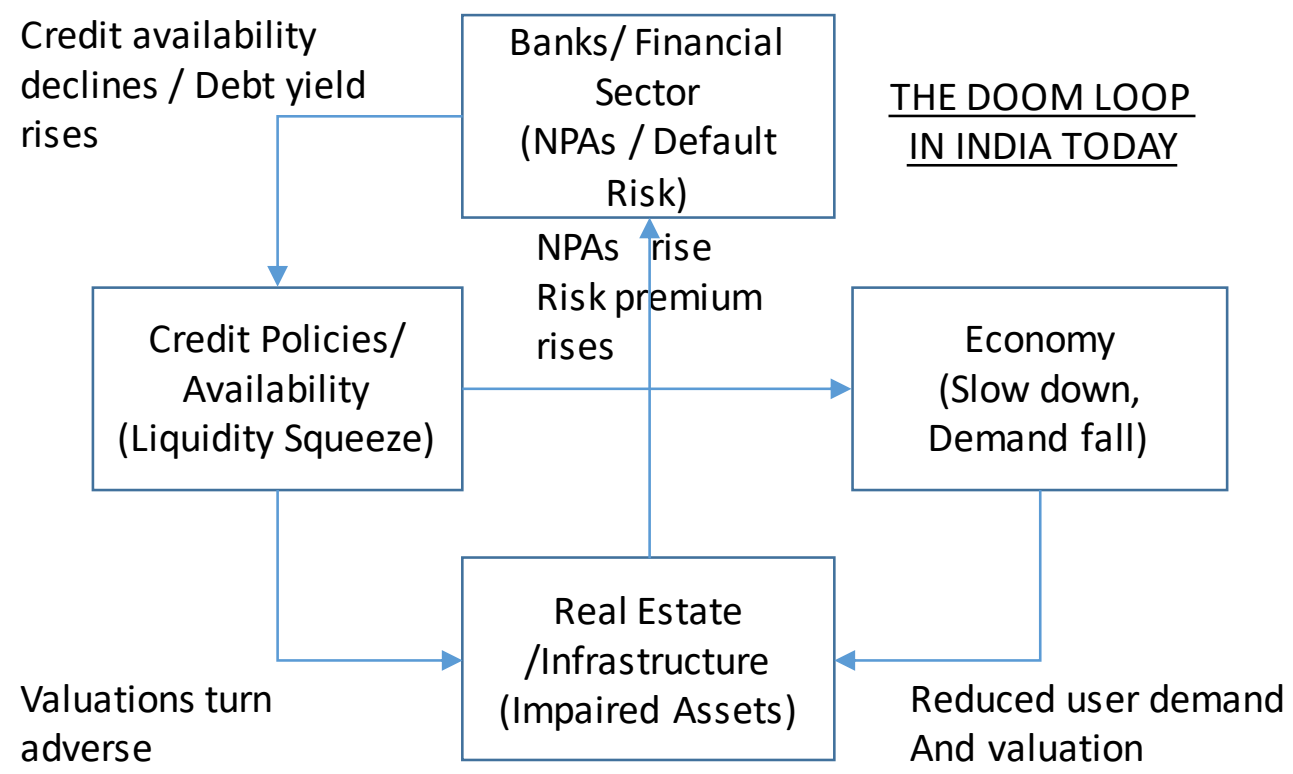

